\title{
A FORMAÇÃO DA NORMALISTA PARA ATUAR COM CRIANÇAS NO MÉXICO: EXPERIÊNCIAS DE MOBILIDADE ACADÊMICA
}

\author{
La formación de la normalista para actuar con niños en Mexico \\ experiencias de movilidad académica
}

\author{
The education of the student teacher to deal with children in Mexico: experience of an \\ academic mobility
}

\author{
María Cristina Lara Bada* \\ María Guadalupe Ñeco Reyna* \\ Vanessa Kusminski*
}

\section{Resumo}

Este artigo é um relato da formação normalista de professores nos Estados Unidos Mexicanos a partir da experiência de mobilidade acadêmica vivida no ano de 2018, no âmbito do Projeto Paulo Freire de Mobilidade Acadêmica para Estudantes de Programas Universitários de Formação de Professores, coordenado pela Organização dos Estados Ibero-americanos (OEI). A formação normalista vivenciada teve por base os estudos em uma Escola Normal mexicana e os estágios com crianças na escola de educação básica. O trabalho revela o contexto vivido, reflete acerca das influências pedagógicas na formação da criança mexicana, possibilitando aprofundar conhecimentos sobre docência e formação de professores.

PALAVRAS-CHAVE: Escola Normal. Formação de Professores. Mobilidade Acadêmica.

\begin{abstract}
This article is a report of teacher education in the United Mexican States based on the experience of an academic mobility lived in 2018, under the Paulo Freire Project on Academic Mobility for Students of University Teacher Education Programs, coordinated by the Organization of IberoAmerican States (OEI). The student teacher education experienced was based on the studies in a

\footnotetext{
* Doutora em Pesquisa no Ensino e aprendizagem de ciências experimentais, sociais e matemáticas pela Universidade de Huelva-Espanha - ES. Mestre em Pesquisa em Psicologia Aplicada na Educação pela "Universidad Veracruzana" - MX. Atualmente é Diretora da Educação Normal do Estado de Veracruz-MX. E-mail: mlarab@msev.gob.mx

* Doutora em Estudos Interculturais pela "Universidad Nacional de Educación a Distancia" (UNED) Madrid/ES. Mestre em Pesquisa em Psicologia Aplicada na Educação pela "Universidad Veracruzana" - MX. Atualmente é Professora da "Benemérita Escuela Normal Veracruzana Enrique C. Rébsamen" - MX. E-mail: niecoreynama@ hotmail.com

* Acadêmica do curso de Licenciatura em Pedagogia da Faculdade de Educação (FAED), da Universidade Federal da Grande Dourados (UFGD), membro do Grupo de Pesquisa Educação e Processo Civilizador" (GPEPC) e bolsista pelo Programa Institucional de Bolsas de Iniciação Científica PIBIC/CNPq. E-mail: vanessakusminski1@gmail.com
} 
mexican Normal School, well as internships with children in elementary school. This work show the context experienced, reflects the pedagogical influences in the education of a mexican child, allowing deeper understanding of teaching and teacher education.

KEYWORDS: Normal School. Teachers Education. Academic Mobility.

\section{Resumen}

Este artículo es un relato de la formación de profesores normalistas en los Estados Unidos Mexicanos a partir de una experiencia de movilidad académica vivida en el año de 2018, en el ámbito del Proyecto Paulo Freire de Movilidad Académica para Estudiantes de Programas de formación de docentes universitarios, coordinado por la Organización de Estados Iberoamericanos para la Educación, la Ciencia y la Cultura (OEI). La formación Normalista vivenciada tuvo por base los estudios en una Escuela Normal mexicana y prácticas con niños en escuelas de educación básica. El trabajo revela el contexto vivido, reflexiona acerca de las influencias pedagógicas en la formación de la niñez mexicana, posibilitando profundizar conocimientos sobe docencia y su respectiva formación

PALABRAS-CLAVE: Escuela Normal. Formación docente. Movilidad académica.

\section{INTRODUÇÃO}

\section{Mobilidade internacional na formação de professores: a história de um projeto de intercâmbio}

Escrever sobre a realidade de um país, com o foco somente em alguns aspectos ou fragmentos, é uma experiência interessante e difícil, e é justamente isso que pretendemos fazer neste artigo: descrever as impressões de uma viagem de caráter científico, realizada com o intuito de conhecer uma parcela da educação mexicana no âmbito do Projeto Paulo Freire de Mobilidade Acadêmica para Estudantes de Programas Universitários de Formação de Professores, coordenado pela Organização dos Estados Ibero-americanos (OEI). Este artigo é resultado de uma viagem realizada entre os meses de agosto e dezembro de 2018 à cidade de Xalapa no Estado de Vera Cruz, México.

Compreendemos - falo em parceria com as professoras mexicanas que me apoiaram, que foram minhas tutoras nessa empreitada e que assinam comigo este trabalho-, os limites de um trabalho como este, considerando que mesmo tendo feito apenas uma viagem para Xalapa, por um período curto, sempre me posicionei com um olhar envolvido e interessado em apreender o máximo da experiência que me oportunizaram. Procurei conhecer e vivenciar experiências pedagógicas que pudessem trazer contribuições à pesquisa e à formação de profissionais na educação brasileira - objeto de estudo e pesquisa com a qual tenho me envolvido na formação em Pedagogia no Brasil, como discente da licenciatura na Universidade Federal da Grande Dourados/MS.

Nesse contexto, penso que toda experiência vivida trouxe elementos que me possibilitaram, de modo cuidadoso, sem incorrer em julgamentos prévios e direcionados, 
descrever a viagem destacando especialmente a formação da normalista professora nos Estados Unidos Mexicanos, pois aprender e atuar na escola de formação educacional no México proporcionou uma experiência única, impactante e relevante na minha própria formação docente. Destaco, de modo geral, o contexto cultural, educacional, político e, de modo particular, as festividades, os ritos acadêmicos, a organização institucional, as aulas e o relacionamento com os colegas. Vivi situações que por vezes me levavam ao inevitável desejo de fazer "comparações" com o meu próprio contexto.

Retomando ao contexto mexicano, o presente trabalho advém de experiências acadêmicas vivenciadas no segundo semestre do ano 2018. Como mencionado, o intercâmbio estudantil a partir do projeto Paulo Freire de Mobilidade acadêmica, coordenado pela Organização de Estados Ibero-Americanos (OEI), destina-se ao fortalecimento da formação docente nos países integrados a essa organização, por meio de mobilidades acadêmicas internacionais para estudantes de graduação e pós-graduação de cursos voltados à profissão docente, e visa enriquecer o processo de ensino aprendizagem.

No período citado, ausentei-me do contexto brasileiro de formação no curso de Pedagogia, licenciatura na Universidade Federal da Grande Dourados/MS, para viver um período no México, onde fui recebida na cidade de Xalapa, estado de Veracruz, pela Benemérita Escuela Normal Veracruzana Enrique C. Rébsamen (BENV), uma escola centenária que goza de prestígio no estado de Veracruz e também no país.

Durante a mobilidade, vivenciei o cotidiano de uma estudante normalista e tive uma experiência que compreendia cursar a estrutura curricular de um semestre em andamento, frequentar estágios em escolas de educação primária, além participar de atividades extracurriculares oferecidas pela instituição. Fui uma aluna normalista, como qualquer outra da Escuela Normal Veracruzana - experiência única na minha trajetória acadêmica de formação e de intercâmbio acadêmico.

Nesse aspecto, é indiscutível a importância da mobilidade acadêmica na formação docente frente à oportunidade de conhecer, vivenciar e analisar outros contextos educativos, ampliando as possibilidades de mudar nossas concepções sobre o outro, podendo, assim, compreender e experimentar a diversidade humana na prática.

\section{México e a formação de professores: olhares em formação}

Os Estados Unidos Mexicanos, mais conhecido como México, possui em torno de 119,9 milhões de habitantes (INEGI ${ }^{1}$, 2015) e chama atenção por sua diversidade étnica, cultural e também por toda herança histórica que possui com seus dois mil sítios arqueológicos (GOB.mx) ${ }^{2}$ e suas 68 línguas indígenas. Dentre suas virtudes, destacamos a comida mexicana, que ganhou destaque devido ao título de patrimônio cultural imaterial da humanidade concedido pela Organização das Nações Unidas para a Educação, a Ciência e a Cultura (UNESCO, 2010), e que é conhecida em todos os lugares, inclusive no Brasil, sendo uma iguaria muito prestigiada.

O estado de Veracruz é um exemplo de toda essa riqueza e diversidade pois possui 10 regiões (Huasteca Alta, Huasteca Baja, Totonaca, Nautla, Capital, Sotavento, Montañas, Papaloapan, Los Tuxtlas, Olmeca), cada uma delas dotadas de peculiaridades quanto à

\footnotetext{
${ }^{1}$ Instituto Nacional de Estadística y Geografía.

${ }^{2}$ Governo Mexicano.
} 
gastronomia, danças, músicas e festividades - todas influenciadas e herdadas pelos povos pré-hispânicos (Olmecas, Totonacas, Toltecas, Otomies e Huastecos).

A imensa diversidade cultural expõe a impossibilidade de falar da formação mexicana sem considerar os aspectos histórico-culturais desse povo. Isto posto, nosso propósito é apresentar a educação e a experiência vivida em uma instituição específica - no caso, as Escolas Normais. Ao apresentá-las, falamos de instituições pioneiras e históricas de grande relevância para a formação docente no México e, consequentemente, para a formação escolar das crianças mexicanas.

Desde sua criação no séc. XIX, as Escolas Normais passaram por reformas e mudanças curriculares, de acordo com as necessidades de cada época, uma das quais permitiu aos estudantes, ao saírem da escola secundária, ingressar na Escola Normal e obter, ao término, o título de "bachillerato" e de professor, simultaneamente. A partir de 1984, em mais uma reforma do ensino normalista, o grau básico é elevado ao de licenciatura e as Escolas Normais passam a ser vistas como instituições de nível superior (CAZALES, 2015).

Atualmente, as licenciaturas das Escolas Normais e os cursos de Pedagogia são os principais meios para a formação docente no México e, conforme o artigo $3^{\circ}$ da Constituição Política dos Estados Unidos Mexicanos, os planos e programas de estudos para Educação Básica e Normal são determinados pelo Estado: "el Ejecutivo Federal determinará los planes y programas de estudio de la educación preescolar, primaria, secundaria y normal para toda la República". Já em relação às universidades, a lei outorga autonomia na construção dos planos e programas de ensino.

Pude observar, na legislação e in loco, que existem divergências entre as formações, e que estas se refletem especialmente no cotidiano da formação da criança. Apesar do enfoque do curso de Pedagogia ser mais teórico formando o bacharel, e as atividades de prática docente não serem priorizadas em seu currículo, estes profissionais pedagogos podem atuar tanto quanto as normalistas que têm, na sua formação, uma carga horária maior voltada para a prática. Não pretendo me aprofundar nessa temática, pois estive na Escola Normal, que tem o mesmo status de curso superior, e era compatível com a licenciatura que estou cursando no Brasil. Portanto, tais diferenças na formação docente mexicana se expõem no cotidiano do atendimento e da prática na educação da criança mexicana, tendo em vista as distintas formações que os docentes recebem.

Em todos os contextos, os planos e programas de estudos são nacionais, assim como os exemplares dos livros didáticos são igualmente distribuídos para todo país conforme o grau de estudos. Ou seja, o livro de espanhol utilizado pelo primeiro grau de uma escola de Xalapa, localizada no leste do México, é o mesmo utilizado na cidade de Hermosillo, a noroeste do país.

Sobre a proposta de livro didático, tive a oportunidade de participar de um evento relacionado ao Dia Nacional do Livro, no dia 14 de novembro, realizado na biblioteca central da BENV. Na ocasião, apreciei uma exposição de livros antigos, e tomei conhecimento de uma estatística indicando que até o ano 2018, sete milhões de exemplares foram entregues nas escolas mexicanas. Também assisti a uma mesa composta por três professores que expuseram em imagens e comentários os chamados Libros de textos gratuitos - os livros didáticos do México. Foi interessante perceber que diante do exposto, havia uma nostalgia demonstrada pelos ouvintes a cada livro apresentado, e atingiam pessoas de idades entre 19 e 60 anos, aproximadamente, de diferentes regiões do país. 
Semelhante experiência presenciei no Brasil com a exposição da cartilha Caminho Suave, realizada em uma aula de história da educação brasileira no primeiro semestre de 2017, no curso de Pedagogia.

Algumas questões podem ser discutidas, tal como a formação e seus aspectos distintos, feita em paralelo a um programa de livros didáticos para todo o país, sem levar em consideração a diversidade de cada região. No entanto, preocupações quanto à conservação das particularidades histórico-culturais do México, e especificamente do estado de Veracruz, faziam parte da formação normalista, da qual participei, observando um movimento em direção às iniciativas focadas em um trabalho intercultural que procurava considerar os docentes formados e prontos para atuar em diversos contextos, como áreas rurais, vilarejos, aldeias indígenas, entre outros.

\section{A Escola Normal mexicana: o cotidiano de uma normalista}

Neste tópico, apresentarei a rotina de um/uma estudante normalista partindo da experiência vivida durante o período de estudos realizado no $5^{\circ}$ semestre da Licenciatura em Educação Primária, onde cursei oito disciplinas. Antecipo afirmando que a formação normalista está intimamente ligada com a prática docente.

A Benemérita Escuela Normal Veracruzana Enrique C. Rébsamen foi a primeira Escola Normal mexicana do tipo moderno, fundada ${ }^{3}$ pelo professor Suíço Enrique Conrado Rébsamen Egloff. Em 2018, completou 132 anos de sua inauguração, e é referência na história da formação de professores no país.

A formação do professorado nas Escolas Normais é dividida por licenciaturas. No caso da BENV, são oferecidas cinco: "Educación Preescolar", "Educación Primaria", "Educación Secundaria", "Educación Especial" e "Educación Física". O tempo de duração de cada uma é de quatro anos, divididos em oito semestres.

No caso da "Educación Primaria", os estudantes concluintes dessa licenciatura podem atuar com o que corresponde do $1^{\circ}$ ao $6^{\circ}$ ano do ensino fundamental no Brasil. Quanto à estrutura curricular, está distribuída em disciplinas de cunho psicopedagógico, língua adicional e tecnologias da informação e comunicação, optativas, sendo a preparação voltada para o ensino e aprendizagem e para prática profissional as mais intensivas, como disposto no quadro abaixo:

Quadro 1- Estrutura Curricular da Licenciatura em Educação Primária

$1^{\circ}$ Semestre $\quad 2^{\circ}$ Semestre $\quad 3^{\circ}$ Semestre $\quad 4^{\circ}$ Semestre $\quad 5^{\circ}$ Semestre $\quad 6^{\circ}$ Semestre $\quad 7^{\circ}$ Semestre $\quad 8^{\circ}$ Semestre

\begin{tabular}{|c|c|c|c|c|c|c|c|}
\hline $\begin{array}{l}\text { El sujeto y su } \\
\text { formación } \\
\text { profesional } \\
\text { como docente } \\
4 / 4.5\end{array}$ & $\begin{array}{c}\text { Planeación } \\
\text { educativa } \\
4 / 4.5\end{array}$ & $\begin{array}{c}\text { Adecuación } \\
\text { curricular } \\
4 / 4.5\end{array}$ & $\begin{array}{c}\text { Teoría } \\
\text { pedagógica } \\
4 / 4.5\end{array}$ & $\begin{array}{c}\text { Herramientas } \\
\text { básicas para la } \\
\text { investigación } \\
\text { educativa } \\
4 / 4.5\end{array}$ & $\begin{array}{l}\text { Filosofía de la } \\
\text { educación } \\
4 / 4.5\end{array}$ & $\begin{array}{c}\text { Planeación y } \\
\text { gestión } \\
\text { educativa } \\
4 / 4.5\end{array}$ & $\begin{array}{l}\text { Trabajo de } \\
\text { titulación } \\
\qquad 4 / 3.6\end{array}$ \\
\hline
\end{tabular}

${ }^{3}$ A trajetória da fundação da escola está disponível em site próprio. 


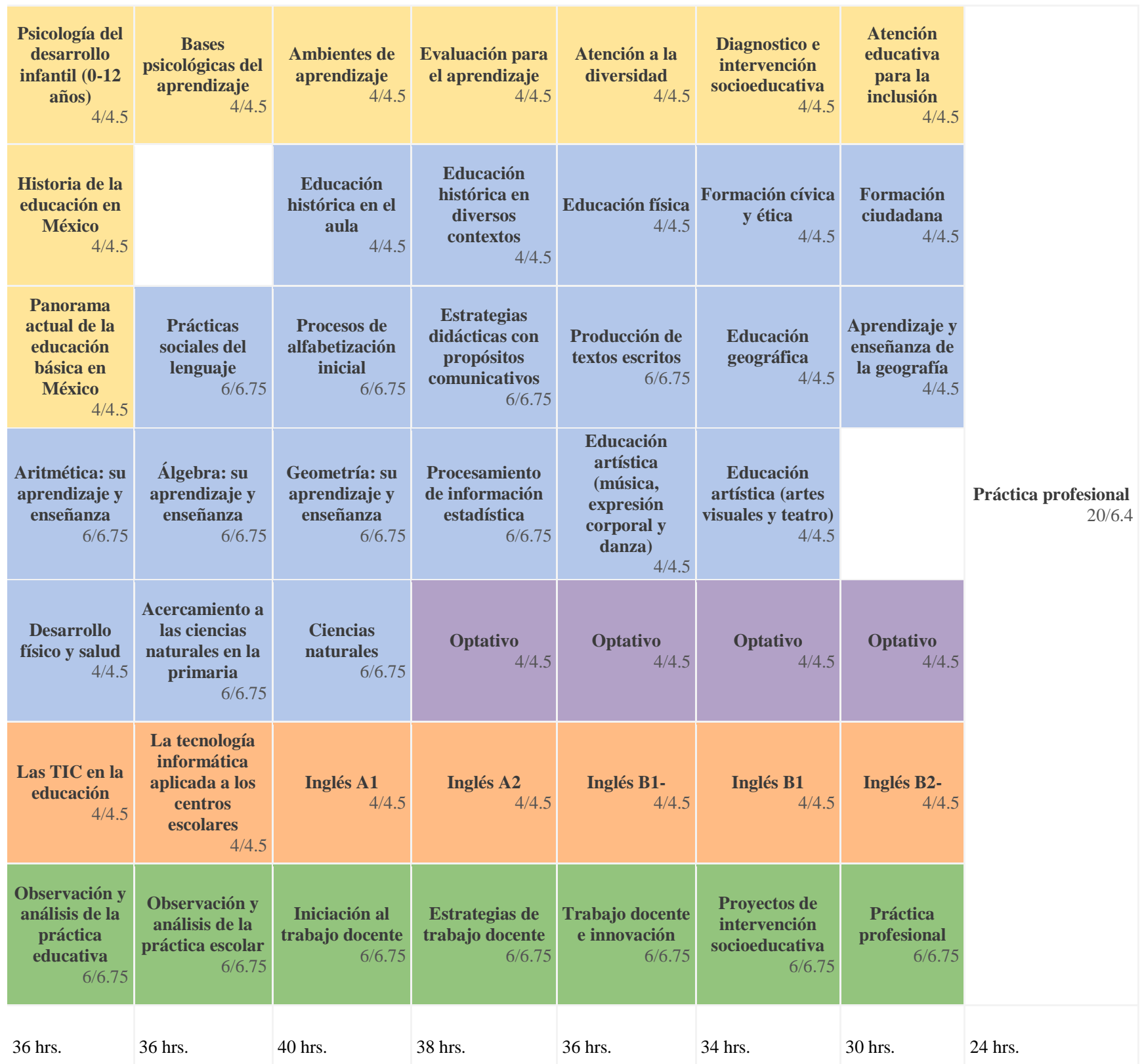

\section{Psicopedagógico}

Preparación para la Enseñanza y el Aprendizaje

Lengua Adicional y Tecnologías de la Información y la Comunicación

Práctica Profesional

Optativos

Fonte: Benemérita Escuela Normal Veracruzana "Enrique C. Rébsamen”- Gob. MX. 
Durante o período letivo, participei da turma do $5^{\circ}$ semestre compreendendo as disciplinas "Herramientas básicas para la investigación educativa", "Atención a la diversidade", "Educación física", "Producción de textos escritos", "Educación artística (música, expresión corporal y danza)", "Conocimiento de la entidade", "Inglés B1" e "Trabajo docente e innovación".

Todas essas disciplinas foram cursadas em um cronograma estabelecido pela instituição e oferecidas exclusivamente às turmas de $5^{\circ}$ semestre. As aulas aconteciam de segunda a sexta-feira, com início às $7 \mathrm{~h}$ e término às $15 \mathrm{~h} 30$, com um intervalo de 30 minutos às 11h. Também havia espaço curricular semanal (todas as quartas-feiras) destinado à realização de atividades extras, oferecidas pela escola. As atividades extras curriculares (talleres) e esportivas eram ofertadas com horários posteriores ao término das aulas, conforme divulgados previamente no Boletín Normalista, de setembro de 2018:

\section{Figura 1 - Cursos extra curriculares oferecidos pela escola}

\begin{tabular}{|c|c|c|c|}
\hline TALLER & DÍA & HORARIO & LUGAR \\
\hline $\begin{array}{l}\text { Ballet folklórico de la } \\
\text { BENV }\end{array}$ & $\begin{array}{l}\text { Lunes, martes y } \\
\text { miércoles }\end{array}$ & $\begin{array}{c}18: 00 \text { a } \\
20: 00\end{array}$ & Sala de danza \\
\hline $\begin{array}{c}\text { Taller de } \\
\text { manualidades }\end{array}$ & Lunes & $\begin{array}{c}17: 00 \mathrm{a} \\
18: 30\end{array}$ & Unidad de Apoyos didácticos \\
\hline $\begin{array}{l}\text { Taller de técnicas } \\
\text { gráfico-plásticas }\end{array}$ & Martes & $\begin{array}{l}17: 00 \mathrm{a} \\
18: 30\end{array}$ & Unidad de Apoyos didácticos \\
\hline $\begin{array}{l}\text { Lengua de sef́as } \\
\text { mexicana }\end{array}$ & Lunes & $\begin{array}{c}16: 00 \mathrm{a} \\
18: 00\end{array}$ & $\begin{array}{c}\text { Información en Extensión y Difusión de } \\
\text { la Cultura }\end{array}$ \\
\hline Lengua Náhuatl & Lunes & $\begin{array}{c}16: 00 \mathrm{a} \\
18: 00\end{array}$ & Edificio "A" Aula 4. \\
\hline Guitarra & Miércoles y jueves & $\begin{array}{l}16: 00 \mathrm{a} \\
18: 00\end{array}$ & Edificio "A" Aula 3. \\
\hline Narración oral & Lunes a jueves & $\begin{array}{c}17: 00 \mathrm{a} \\
19: 00\end{array}$ & Edificio "B". \\
\hline Coro normalista & Miércoles y jueves & $\begin{array}{c}16: 00 \mathrm{a} \\
18: 00\end{array}$ & Edificio "A" Aula 3. \\
\hline $\begin{array}{c}\text { Fotografía con cámara } \\
\text { y teléfono celular }\end{array}$ & Martes y jueves & $\begin{array}{c}16: 00 \text { a } \\
18: 00\end{array}$ & Edificio "A" Aula 4. \\
\hline $\begin{array}{l}\text { Talleres de danza del } \\
\text { Ateneo Normalista }\end{array}$ & Martes y jueves & $\begin{array}{c}16: 30 \mathrm{a} \\
18: 00\end{array}$ & EPPA \\
\hline Taller de son jarocho & Jueves y viernes & $\begin{array}{c}17: 00 \mathrm{a} \\
18: 30\end{array}$ & Aula circular 41. \\
\hline \multirow{2}{*}{$\begin{array}{l}\text { Compafía de danza del } \\
\text { Ateneo Normalista }\end{array}$} & Jueves y viernes & $\begin{array}{l}18: 00 \mathrm{a} \\
20: 00\end{array}$ & \multirow{2}{*}{ Sala de danza } \\
\hline & Sábado & $\begin{array}{l}09: 00 a \\
12: 00\end{array}$ & \\
\hline
\end{tabular}

Fonte: Benemérita Escuela Normal Veracruzana "Enrique C. Rébsamen”.

A escola não só ofertava, como também estimulava a participação dos discentes nessas atividades, conforme o Boletín Normalista, de outubro 2018:

Hacemos la invitación para todos quienes están inscritos en los talleres vespertinos para que perseveren en las sesiones y mantengan continuidad en su formación complementaria. Y a quienes todavía no están inscritos, les invitamos pasar a nuestra oficina para que opten por alguno de nuestros talleres vespertinos. ¡Estás a tiempo! (BENV, 2018). 
Ainda sobre o curso e a referida escola, os estudantes normalistas deveriam seguir as normas dispostas no regulamento interno e demais princípios que caracterizam a instituição, como exemplo, o uso do uniforme obrigatório, especialmente em atividades externas da escola. Havia dois tipos de uniforme: o tradicional e o de gala. Este último é imprescindível em ocasiões como "Honores a bandeira" e as apresentações nas escolas de estágio. "Honores a bandeira" é um evento característico das escolas de Educação Básica e das Escolas Normais mexicanas: ambas seguem o mesmo protocolo. Como um dos conteúdos da formação, esse evento é parte do curso pois os/as alunos/as normalistas futuramente terão que executar a cerimônia na escola em que atuarão. Essa atividade é parte da formação na Escola Normal, mas não nos cursos de Pedagogia na universidade.

Podemos perceber, na experiência vivida, que o elemento patriotismo nos pareceu muito forte entre os grupos com os quais convivi e, por certo, isso se deve ao que foi aprendido na escola desde a infância, como valor da cultura escolar mexicana. Como parte da formação, esses grupos, conforme Norbert Elias, possivelmente façam parte de um processo civilizador nas variáveis e costumes de um determinado povo ou grupo social. Segundo este autor - embora aparentemente valores, princípios, modos e costumes nos cheguem, ao que nos parece, prontos e acabados, formando nossa percepção -, é num processo, ou em parte dele, que estamos envolvidos desde os primeiros anos de vida (ELIAS, 2011). Diante disso, fica evidente a presença desse patriotismo e a reprodução dele no processo formativo na educação das crianças.

\section{Formação normalista e as práticas de estágios: experiências vivenciadas}

Ao normalista da Licenciatura Primaria, bem como das demais licenciaturas, são requisitos obrigatórios as "Jornadas de prácticas", que consistem em dois períodos de estágios em escolas de educação básica, orientados por uma disciplina com uma base teórica anterior às observações e estágios na escola. No caso do grupo em que pude estar inserida, a disciplina que orientou as práticas foi "Trabajo docente e innovación".

Por meio dessa experiência, percebi como as jornadas são metódicas e organizadas, o que nos permitia estar inseridos nas práticas da escola. Primeiro, tivemos aulas formais com discussão teórica e textos que buscavam favorecer práticas inovadoras na educação, sendo esta a temática central na disciplina. Próximo ao período da referida jornada, foi estabelecido um espaço de diálogo em que os estudantes escolheram a faixa etária e o grau em que desejavam atuar. Posteriormente, desenvolvemos um planejamento de aulas para as primeiras duas semanas nas quais atuaríamos como docente da turma escolhida.

A jornada iniciava com a apresentação na escola em que foi negociada a permanência dos/as normalistas em formação. A professora responsável pela disciplina de estágio nos pediu para confeccionar algo como uma lembrança/carta apresentando nossas expectativas e objetivos para presentear a futura professora tutora na Escola Primária, e solicitou que utilizássemos o uniforme de gala.

Na Escola Primária, recebemos por parte da Direção, as instruções referentes ao funcionamento da instituição. Em seguida, fomos até as salas de aula nos apresentar às crianças e seus respectivos professores tutores com quem iríamos trabalhar. No meu caso, escolhi o $1^{\circ} \mathrm{C}^{4}$. Ao me apresentar na sala, fui muito bem recebida pela professora e pelas

\footnotetext{
${ }^{4}$ Correspondente ao primeiro ano do ensino fundamental do Brasil.
} 
crianças, indaguei se me aceitariam por duas semanas como professora na escola e em resposta - entre sorrisos e inquietudes -, proferiram um cálido sim.

Antes de iniciar as aulas práticas, tivemos dois dias de observações, nos quais teríamos que fazer um diagnóstico da escola, o perfil da turma e solicitar os conteúdos a trabalhar durante a semana em que estaríamos atuando com as crianças. Feito o diagnóstico, perfil e conteúdos a trabalhar, pudemos dar sequência ao planejamento idealizado durante as aulas na Escola Normal.

A escola na qual atuamos localizava-se em um bairro de classe média baixa, e se apresentava com 24 profissionais, 507 alunos e 17 "grupos" - turmas de $1^{\circ}$ ao $6^{\circ}$ anos escolares. $\mathrm{O}$ turno de funcionamento era matutino, pois no período vespertino a instituição estava organizada como escola secundária. Interessante que os dois turnos, distintos, acontecem no mesmo prédio mas com uma gestão diferente. Ou seja, são duas escolas em um mesmo prédio, segundo relatos de colegas normalistas, essa é uma característica da maioria das escolas públicas da cidade.

As aulas se iniciam às $8 \mathrm{~h}$ e terminam às $12 \mathrm{~h}$, com 30 minutos de intervalo às $11 \mathrm{~h}$. Todas as segundas feiras às $8 \mathrm{~h}$, pontualmente, têm início as atividades relativas à homenagem à bandeira. Nestes momentos, pude observar, in loco, a referida cerimônia. Alunos que chegam atrasados devem esperar do lado de fora da instituição até o término do evento, que ocorre às segundas-feiras, e a cada evento uma turma fica responsável pela organização e apresentação da homenagem à bandeira.

A ordem da homenagem seguia um protocolo no qual, primeiro o diretor dá as boasvindas, na sequência as crianças leem textos em homenagem ao país, ao estado ou à cidade. Em seguida, fazem uma marcha com a bandeira com uma coreografia padrão que ensaiaram durante a semana anterior e, por fim, cantam os hinos nacional do México, do estado e da cidade. Esta cerimônia ocorre sempre às segundas-feiras.

Durante a semana - de terça a sexta-feira, às $8 \mathrm{~h}$ da manhã -, se realiza uma atividade chamada activación, contendo uma série de exercício ou coreografias executadas com música e, tal como a homenagem à bandeira, também cada turma assume um determinado dia.

No $1^{\circ}$ ano, trabalhei com crianças de 5 e 6 anos de idade, em uma sala com 29 crianças. As aulas estavam organizadas em três ou quatro disciplinas por dia, sendo elas: "Español", "Educación física", "Conocimiento del médio", "Matemáticas", "Educación Socioemocional", "Artes" e os "Clubs". Esta proposta curricular foi implantada pelo novo modelo educativo que entrou em vigor no ano de 2018.

El modelo que se deriva de la Reforma Educativa, es decir, la forma en que se articulan los componentes del sistema, desde la gestión hasta el planteamiento curricular y pedagógico, tiene como último una educación de calidad con equidad donde se pongan los aprendizajes y la formación de niñas, niños y jóvenes en el centro de todos los esfuerzos educativos (SEP, 2018, p. 1).

Partindo dessas perspectivas, nos instigávamos em buscar práticas mais inovadoras, onde "só existe saber na invenção, na reinvenção, na busca inquieta, impaciente, permanente, que os homens fazem no mundo, com o mundo e com os outros" (FREIRE,

\footnotetext{
${ }^{5}$ Aulas em que os alunos trocam de turmas e estudam temas como "Alimentação saudável", "Eucação ambiental", "Línguas de sinais", e outros.
} 
1987, p. 33). Assim, desenvolvi atividades de movimento do corpo e da mente e verifiquei a participação e a surpresa das crianças com as atividades trabalhadas. Ao regressar às aulas na Escola Normal, discutíamos sobre os acontecimentos em cada turma observada, e tais discussões fomentavam os processos de troca e intercâmbio mútuo, importantes na formação de um/a normalista. No processo de retroalimentação de uma jornada de prática, essas exposições dos momentos vividos na escola eram importantes para ampliar o conhecimento e auxiliar os futuros professores a desenvolver seu potencial docente.

\section{CONSIDERAÇÕES FINAIS}

A minha percepção da BENV foi de uma grande universidade dedicada exclusivamente à formação de professores. Atenta à diversidade cultural e à educação, fiquei muito satisfeita em conhecer tantos estudantes apaixonados pela profissão docente. Foi uma oportunidade ímpar de compartilhar conhecimentos com pessoas e profissionais que acreditam na educação e a veem como a base de uma sociedade tolerante e igualitária.

Todas as experiências vividas na mobilidade me fizeram refletir sobre a educação brasileira e me fortaleceram em todos os âmbitos, tanto pessoal como profissional, a continuar na formação. Muitos momentos fizeram com que eu questionasse conceitos, ampliando meus conhecimentos sobre a formação docente e a profissão professora. Muitas certezas e algumas incertezas pairam sobre minha formação, mas, um fato assertivo devo mencionar: a educação sobrevive a tantos ataques porque existem profissionais fortes para "carregá-la" em tempos de crise.

O modo como na Benemérita Escuela Normal Veracruzana, a experiência docente é organizada e proposta na disciplina de estágio foi muito interessante, pois iniciamos com embasamento teórico sobre a atuação buscando formas de inovar na educação, planejamos as aulas e assumimos as turmas por duas semanas; retornando à escola, fizemos uma retroalimentação e regressamos novamente à escola para desenvolver o "projeto inovador" com a turma. Este processo nos levou à percepção concreta da reflexão-ação-reflexão aperfeiçoando o trabalho.

Concluo, apontando que, na minha concepção, um dos pontos mais relevantes da formação normalista no México é a íntima relação estabelecida com a prática docente, tanto nas disciplinas cursadas como na vivência na escola, bem como nos conhecimentos compartilhados com os colegas de outras licenciaturas e os estágios realizados ao longo do curso. O estudante normalista é formado seguindo algumas premissas calcadas nas tradições - herança histórica - como o patriotismo e valorização dos ritos tradicionais que, na escola da infância, se mesclam ao desejo e à necessidade de buscar a inovação propalada pelos documentos e propostas curriculares mais atuais. De qualquer modo, toda experiência e cultura vão à direção de fazer uma escola atuante na formação da criança mexicana e dos seus docentes, a qual eu tive a alegria de partilhar.

\section{REFERÊNCIAS}

BENV - La Fundación De La Escuela Normal Veracruzana. Disponível em: <http://www.benv.edu.mx/inicio/index.php>. Acesso em: 27 jan. 2019. 
BENV - Boletín Normalista. n. 29, set. 2018. Disponível em: <http://www.benv.edu. mx/boletines/__PDF__2018__/boletin_29_2018.pdf>. Acesso em: 02 fev. 2019.

BENV - Boletín Normalista. n. 33, out. 2018. Disponível em: <http://www.benv.edu.mx/ boletines/__PDF__2018__/boletin_33_2018.pdf>. Acesso em: 02 fev. 2019.

CAZALES, Z. N. Formación de profesores en las Escuelas Normales de México: siglo XX. Revista Historia de la Educación Latinoamericana, v. 17, n. 25, p. 17-34. 25, jul./dez. 2015. Disponível em: <https://www.redalyc.org/pdf/869/86941142002.pdf>. Acesso em: 25 jan. 2019.

DUCOING, P. Origen de la Escuela Normal Superior de México. Rhela. v. 6. p. 39-56, 2004. Disponível em: < https://www.redalyc.org/html/869/86900604/>. Acesso em: 02 fev. 2019.

ELIAS, N. O processo civilizador: uma história dos costumes. Tradução: Ruy Jungmann. 2. ed. v. 1, Rio de Janeiro: Jorge Zahar, 2011.

FREIRE, P. Pedagogia do oprimido. 17. ed. Rio de Janeiro, Paz e Terra, 1987.

INEGI - Instituto Nacional de Estadística y Geografía. 2015. Disponível em: <https://www.inegi.org.mx/temas/estructura/>. Acesso em: 26 jan. 2019.

MÉXICO. Constitución Política de los Estados Unidos Mexicanos. DOF 5/2/1917. Disponível em: <https://www.juridicas.unam.mx/legislacion/ordenamiento/constitucionpolitica-de-los-estados-unidos-mexicanos\#10538>. Acesso em: 26 jan. 2019.

SEP. Nuevo Modelo Educativo. 2018. Disponível em: <https://www.gob.mx/sep/documentos/ nuevo-modelo-educativo-99339>. Acesso em: 27 jan. 2019.

UNESCO - La cocina tradicional mexicana, cultura comunitaria, ancestral y viva: el paradigma de Michoacán. 2010. Disponível em: <https://ich.unesco.org/es/RL/la-cocinatradicional-mexicana-cultura-comunitaria-ancestral-y-viva-el-paradigma-de-michoacan00400\# identification>. Acesso em: 02 fev. 2019.

Recebido em: 03/05/2019

Aprovado em: 05/07/2019 